Abstracts on this page have been chosen and

edited by Dr Trevor Watts

DENTAL HEALTH, SOCIOLOGY

\section{Welfare dental intervention improves employment and quality of life}

Hyde S, Satariano WA et al. J Dent Res 2006; 85: 79-84

A programme of dental rehabilitation doubled the likelihood of satisfactory employment.

In San Francisco, a special benefit programme is directed towards employable single indigent adults. In 1999, a dental aspect was added to this, and in the next 18 months, 379 people requested dental services, of whom 377 agreed to participate in the present study. Dental treatment was completed by 265 of these. Twothirds of participants were male and about half were African American.

At baseline, those who completed treatment had more missing teeth and fewer decayed teeth than those who did not. Oral health related quality of life improved in $4 / 5$ of those treated, with marked amelioration of psychological discomfort and disability. Compared with those who never started treatment, of whom half had unfavourable employment outcomes, those with incomplete treatment did not have a significantly improved outcome, but those who completed treatment did (OR 2.0, CI 1.1-3.6). The authors consider that oral health treatment can help to reduce barriers to employment.

doi:10.1038/sj.bdj.4813679

\section{ORAL SURGERY; ORTHODONTICS}

\section{Severe retrognathia as a risk factor for} recent onset painful TMJ disorders among adult females

Miller JR, Manci L et al. J Orthod 2005; 32: 249-256

Abnormal facial morphology may be implicated in TMJ disorders.

Some evidence suggests that abnormal mandibular morphology may be involved in TMJ disorders, either as a cause or a consequence. This study was conducted in a health maintenance organisation in Oregon over a 2 year period, and 29 cases of severe retrognathia were compared with 104 controls.

Patients with recent onset (within 3 yrs) TMJ disorders were more likely to be young, white and less educated. The OR for severe retrognathia in these patients compared with controls was $6.3(\mathrm{CI}$ 1.1-47.5).

The authors conclude that among adult females with severe retrognathia, a large proportion of recent onset TMJ disorders may be attributable to severe retrognathia, although only a small proportion of such disorders is attributable to the condition in the whole population of these adults.

\section{ORAL MEDICINE, RHEUMATOLOGY}

\section{Oral and salivary parameters in patients with rheumatic diseases}

\author{
Helenius LMJ, Meurman JH et al. Acta Odont Scand 2005; 63: 284-293
}

Secondary Sjögren's syndrome (SS) is commoner in these patients.

Secondary SS may occur in various rheumatic diseases. The primary condition may encourage caries and oral mucosal changes. In a Finnish hospital, the oral condition of 77 consecutive rheumatic disease patients (24 with rheumatoid arthritis, 15 with mixed connective tissue disease, 18 with ankylosing spondylitis and 20 with spondyloarthropathy) was compared with 77 matched controls.

In 30 patients, secondary SS was diagnosed, and pocketing (as measured by CPITN) was present in more patients than controls. Patients also had lower salivary flow rates, as well as higher levels of some immunoglobulins and higher levels of salivary yeasts. Subjects with SS had more caries and lactobacilli than those without. The authors consider that the findings relate to salivary gland autoimmune inflammation, and that secondary SS is not the only mechanism by which rheumatic conditions may affect oral health.

doi:10.1038/sj.bdj.4813681

\section{ORAL RADIOLOGY, ORAL SURGERY}

\section{Pre-operative radiographic evaluation of lower third molars with computed tomography}

Öhman A, Kivijärvi K et al. Dentomaxillofac Radiol 2006; 35: 30-35

When conventional radiography is insufficient to determine lower third molar (LM3) relations, a CT scan may be indicated.

Where the inferior alveolar nerve is very closely related to LM3, removal of the latter may injure the nerve in up to $1 / 3$ of cases. A retrospective review was undertaken in a Swedish hospital of 64 patients in whom 90 LM3s had been examined by CT.

The course of the mandibular canal was buccal to LM3 in 31\%, lingual in 33\%, inferior in 26\% and inter-radicular in 10\%. Grooving of the root for the canal was present on $23 \%$ of teeth, a hook was present in $8 \%$, and $86 \%$ of teeth had contact with the lingual cortex. In 16\% of cases, part of the tooth penetrated this cortex.

In 88 teeth for which conventional panoramic views were available, a dark band across the tooth was present in $18 \%$, and indicated contact between the canal and root. Grooving was present in only $48 \%$ of teeth with a dark band, but absence of the band indicated no groove in $91 \%$. The authors recommend a CT scan when interpretation of conventional views is inconclusive, and particularly where a dark band is present.

doi:10.1038/sj.bdj.4813682 